
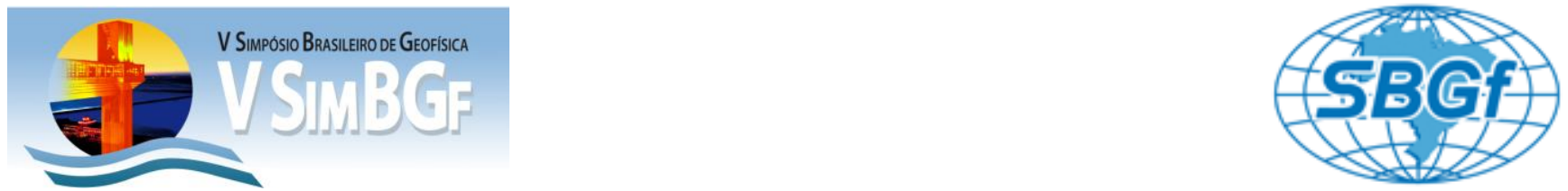

\title{
Modelagem da resposta do perfil de indução usando o método dos elementos finitos na avaliação da cimentação em poços revestidos com fibra de vidro
}

\author{
Alfredo Carrasco, UFF/TEQ - Niterói \& Abel Carrasquilla, UENF/CCT/LENEP - Macaé, RJ
}

Copyright 2012, SBGf - Sociedade Brasileira de Geofísica

Este texto foi preparado para a apresentação no V Simpósio Brasileiro de Geofísica, Salvador, 27 a 29 de novembro de 2012. Seu conteúdo foi revisado pelo Comitê Técnico do V SimBGf, mas não necessariamente representa a opinião da SBGf ou de seus associados. É proibida a reprodução total ou parcial deste material para propósi-

seus associados. E proibida a reprodução total ou

\section{Resumo}

O espaço anular entre o revestimento e a formação geológica é preenchido com cimento para evitar a produção de fluidos indesejáveis. Esse revestimento é, geralmente, fabricado com aço, mas, em ambientes geológicos corrosivos, esse material é substituído por fibra de vidro, a qual é resistente à corrosão. Tradicionalmente, os perfis geofísicos de poço usados na avaliação da integridade da cimentação são os sônicos e ultrasônicos (CBL/VDL). $\mathrm{Na}$ existência de um revestimento de fibra de vidro, a interpretação das respostas dessas técnicas torna-se difícil, devido ao baixo contraste de impedância acústica entre esse tipo de revestimento, o cimento e a formação. Assim, o presente trabalho tem como finalidade estudar a resposta do perfil de indução eletromagnética na avaliação da qualidade da cimentação em poços revestidos com fibra de vidro. Para tal, utilizou-se a técnica dos elementos finitos, usando modelos com a presença de reboco na zona produtiva, zona de invasão, espaço microanular entre a parede externa do revestimento de produção e o cimento, e, uma canalização circular entre o revestimento e a formação. As simulações mostram que a eficiência do método indutivo fica limitado à configuração de bobinas utilizadas e ao tipo de ambiente de poço a ser aplicado.

\section{Introdução}

O uso de revestimentos de fibra de vidro não é novo e tem sido aplicado em varias condições de poço, seja para poços de injeção, instalação de sistemas de elevação artificial e, principalmente, na completação de poços em ambientes corrosivos. Estes tubos estão compostos de $73-75 \%$ fibra de vidro e $25-27 \%$ de resina epóxica (Meyer, 1967). Os revestimentos desse tipo têm obtido uma melhora na sua manufatura, sendo denominados de fibra de vidro de plástico reforçado, o qual consta de uma matriz de resina térmica reforçada com filamentos contínuos de fibra de vidro (Stringfellow, 1987). Materiais desse tipo tem baixa capacidade de dilatação térmica, o que elimina um dois fatores que contribuem na formação de microanular na interface revestimento - cimento. O problema do microanular é definido por Johnson e Pile (2006) como um espaço muito pequeno entre o revestimento e o cimento solido. Normalmente este espaço é muito estreito $(0,002-0,004$ polegadas $)$, mas permite a passagem dos fluidos através dele. Uma das causas da formação deste microanular é devido à diferença da pressão hidrostática originada pela troca do fluido de perfuração de alta densidade, por um fluido de completação mais leve, como a água salgada. Por outro lado, na cimentação nos casos de ambientes corrosivos, se aplicam cimentos densos com classificação API tipo $\mathrm{H}$, os quais possuem maior resistência à penetração de ácidos e pouca perda de fluidos, além de boas propriedades reológicas no bombeio (Millard, 1988).

Em poços revestidos com fibra de vidro, vários tipos de perfis de poço podem ser utilizados:

- radioativos, os quais precisariam de alguma correção para compensar o efeito do hidrogênio presente na resina epoxica da fibra de vidro;

- acústicos, que na avaliação da qualidade da cimentação em poços revestidos de fibra de vidro não tem tido interpretações confiáveis. O tempo de transito na fibra de vidro é aproximadamente $90 \mu \mathrm{seg} / \mathrm{ft}$, valor muito maior que no aço $(56 \mu \mathrm{seg} / \mathrm{ft})$ ou que em formações carbonaticas (47-70 $\mu \mathrm{seg} / \mathrm{ft})$. Portanto os sinais da formação poderiam interferir com os sinais da fibra de vidro nos espaçamentos transmissor-receptor usados (Bowers \& Sydow, 1972). Assim, em relação as ferramentas sônicas, é possível afirmar que a velocidade do sinal usando revestimentos de fibra de vidro, não permite uma clara separação dois sinais do revestimento, cimento e formação. Ferramentas ultrasonicas poderiam ser utilizadas, sendo necessária uma modificação no programa de processamento dos sinais, para esses casos (Da Paula et al, 2007).

- indução, os quais, não encontram dificuldade de penetração do campo eletromagnético devido à alta resistividade elétrica da fibra de vidro, característica que limita o uso do perfil elétrico focalizado do tipo laterolog (Bowers \& Sydow, 1972).

Neste trabalho, usamos o método numérico dos elementos finitos para simular a respostas das ferramentas de indução em cenários que representam ambientes corrosivos com poços revestidos com fibra de vidro. O programa utilizado foi desenvolvido por Kozzolino (2004), o qual considera nas simulações o sistema de coordenadas cilíndricas com simetria axial.

\section{Metodologia}

Como foi mencionado inicialmente, a técnica numérica utilizada neste trabalho para simular as resposta do perfil de indução foi o método dos elementos finitos. Pereira (2009) apresentou um trabalho com o mesmo objetivo, mas utilizando a técnica das equações integrais para ambientes tridimensionais, no estudo de problemas de canalização do cimento. No presente caso, simulou-se o efeito nas respostas do perfil de indução na presença de microanular, do reboco e da canalização circular. Devido à alta penetração do método indutivo para dentro do reservatório, Pereira (2009) fez uma redução do espaçamento entre as bobinas do arranjo $2 \mathrm{C} 40$ de 40 polegadas 
para 20 polegadas, para obter melhor definição das profundidades mais rasas. Neste trabalho foi feita uma diminuição adicional de até 10 polegadas entre as bobinas transmissora e receptora, devido à necessidade de investigar mais raso, cujo espaçamento foi chamado de $2 \mathrm{C} 10$. $\mathrm{Na}$ modelagem, considera-se um revestimento de produção de fibra de vidro de 7 polegadas $(17,8 \mathrm{~cm})$ de diâmetro exterior e meia polegada de espessura (Maki \& Hamilton, 1988), e, uma resistividade de $10^{9} \mathrm{ohm} . \mathrm{m}$ (Rolim, 1996). Por outro lado, o microanular foi considerado com dimensões de $0,01 \mathrm{~cm}$, como definido por Johnson e Pile (2006) e uma resistividade de 300 ohm.m, a qual correspondente ao valor de resistividade do fluido de perfuração base óleo. Para o espaço anular, o qual é preenchido com cimento, tomou-se como referencia o diâmetro da broca (e do poço) de $83 / 4$ ", como o mais apropriado para este revestimento (Bourgoyne et al, 1991), resultando num valor de $6,35 \mathrm{~cm}$ de espessura como media, o qual pode atingir um valor de $12,7 \mathrm{~cm}$ dependendo da litologia, como apresentado por Aulia et. al (2001).

O valor da resistividade do cimento se obtém de estudos laboratoriais, o quais mostram valores que variam, geralmente, entre 1 e $10 \mathrm{ohm}-\mathrm{m}$. Além disso, o cimento possui microporosidade de aproximadamente $35 \%$, o que permite que a água do cimento troque íons com a água da formação. Portanto, uma alta salinidade da água de formação pode, assim, reduzir a resistividade do cimento (Aulia et al, 2001). No modelo assumido, considerou-se um valor de 10 ohm.m para o cimento. No caso do reboco consideraram-se dois casos, o primeiro com um valor de1,27 cm. e, o outro caso, sem a presença do reboco. Segundo Bourgoyne et al (1991), o valor da espessura do reboco é variável e depende do controle de sólidos durante a perfuração e da presença de sólidos inertes no retorno da perfuração, o que pode provocar um aumento na sua espessura e na sua permeabilidade. $O$ valor da resistividade do reboco vai depender muito dos aditivos utilizados na perfuração, assim como das condições de temperatura. Estudos realizados por Johnson e Beyer (1962) mostram baixos valores de resistividade, dando uma media de $1,5 \mathrm{ohm} . \mathrm{m}$, valor que foi considerado na modelagem. Finalmente, na modelagem da zona de invasão considerou-se o caso mais simples, o modelo tipo pistão, com um raio de invasão de $20 \mathrm{~cm}$, por tratarse de fluido de perfuração base óleo.

\section{Resultados}

O modelo a ser simulado aparece na Figura 1, com o qual foram feitas duas simulações diferentes: uma considerando o espaçamento do $0,5 \mathrm{~cm}$ para o microanular adjacente à parede do revestimento e, a outra, sem existência de microanular. Os resultados dessas simulações estão na Figura 2, onde se observa que, mesmo colocando uma espessura de microcanal com um valor muito maior que o definido por Johnson e Pile (2006), a resposta do perfil de indução é indiferente, dando respostas idênticas com a presença ou na ausência do microanular. Para modelar o efeito do reboco, tomou-se também como referencia o esquema da Figura 1 para dois casos, um deles considerando a ausência e o outro com sua presença. As respostas obtidas aparecem na Figura 3, a qual mostra, em vermelho, os resultados sem considerar o reboco e, em azul, levando em conta o efeito do reboco, dando este último, como resultado, valores de resistividades menor para esse intervalo. Para o ultimo caso, sem considerar a presença do reboco, simulou-se a existência de uma zona de canalização circular, como o mostrado na Figura 4, a qual é representada na parte inferior da figura com um valor de 300 ohm.m. A resposta do efeito na canalização circular aparece na Figura 5 (representada pela linha azul), dando valores de resistividades maiores que a resposta sem canalização (linha vermeIha).

\section{Conclusões}

Neste trabalho, foi observado através do três casos estudados, que a aplicação da perfilagem de indução em poços revestidos com fibra de vidro fica limitada às configurações do sistema e às condições de ambiente de poço. Foi assim comprovado que o sistema não é conveniente para avaliar os casos de microanular. No entanto apresenta utilidade na avaliação, de maneira mais eficiente, dos casos de formação de reboco grossos e zonas de canalização. Entretanto, mesmo nesses casos, o sistema precisaria de uma redução entre o espaçamento das bobinas transmissora e receptora.

\section{Agradecimentos}

À Sociedade de Engenheiros de Petróleo (SPE) por disponibilizar artigos para consulta e à Rede CARMOD pelo suporte financeiro de projeto de pesquisa.

\section{Referencias}

Aulia, K.; Poernomo, B.; Richmond, W.C.; Wicaksono, A., Bégin, P.; Benimeli, D.; Dubourg, I.; Rouault, G.; Van der Waal, P.; Boyd, A.; Farag, S.; Ferraris, P.; McDougall, A.; Rosa, M. \& Sharbak, D. 2001. Resistivity behind casing. Oilfield Review, SCHLUMBERGER.

Bourgoyne A., Millheim K, Chenevert M., Young F. S. Applied drilling engineering. Society of Petroleum Engineers. Richardson, Tx. 1991

Bowers, J. H. \& Sydow, J. R. Cemented Fiber Glass Tubulars for downhole well applications. 1972. SPE 4066.

Cozzolino K. Estudo dos efeitos transientes de temperatura e invasão em perfis de poços. Tese de Doutorado. Universidade Federal de Rio de Janeiro. UFRJ. 2004.

Da Paula, J. L., Rodrigues, V. F. e Vicente R. Cement sheath evaluation in nonconventional environment - Case History. 2006, SPE 110383

Johnson D. E. \& Pile K. E. Well logging in nontechnical language. $2^{\text {nd }}$ Edition. Pennwell Corporation. 2006.

Johnson H., \& Beyer R. Further studies in resistivity effects of varios mud additives. SPE 1962_B.

Maki, V. E. \& Hamilton, L. Cement Bond Logs of fiberglass casing. 1988. SPE 18143

Meyer, Jerry W. Case histories of fiber glass tubing in oil field service. 1967. SPE 1965. 
Millard, Robert. New Fiberglass liner completion technique salvages old injection wells for use as WAG injection wells. 1988. SPE 17290.

Pereira, J. C. Avaliação de cimentação em revestimentos de fibra de vidro com auxilio de perfis geofísicos resistivos. Dissertação de Mestrado. Universidade Estadual do Norte Fluminense, UENF. 2009

Rolim, J. G. 1996. Materiais isolantes, Grupo de Sistemas de Potencia - Labspot, UFSC, p. 1-26. (www.labspot.ufsc,br/ jackie/cap4_new.pdf)

Stringfellow, William D. Make-up of fiberglass tubulars. 1987. SPE. 17272.

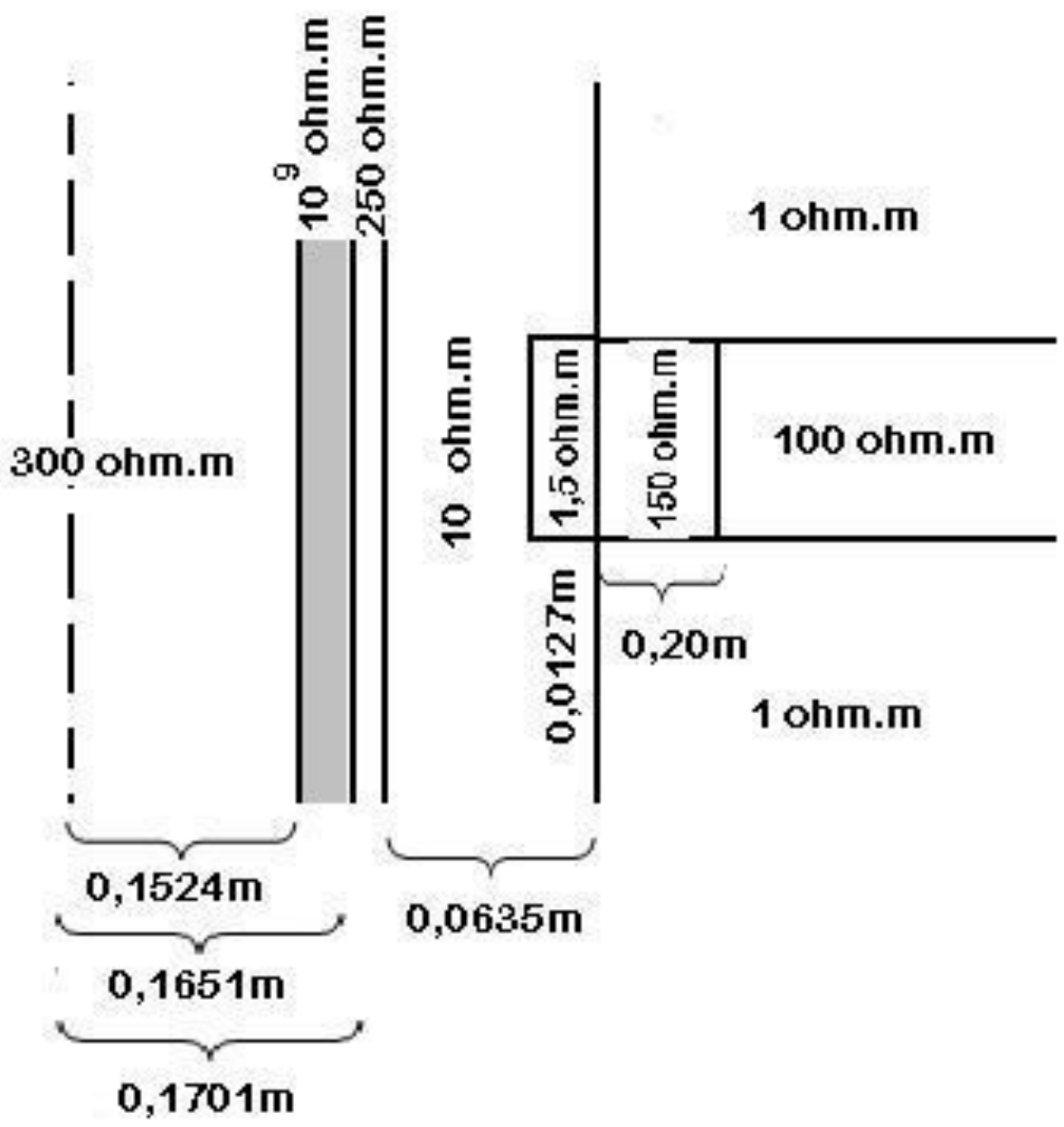

Figura 1. Distribuição de Resistividades 


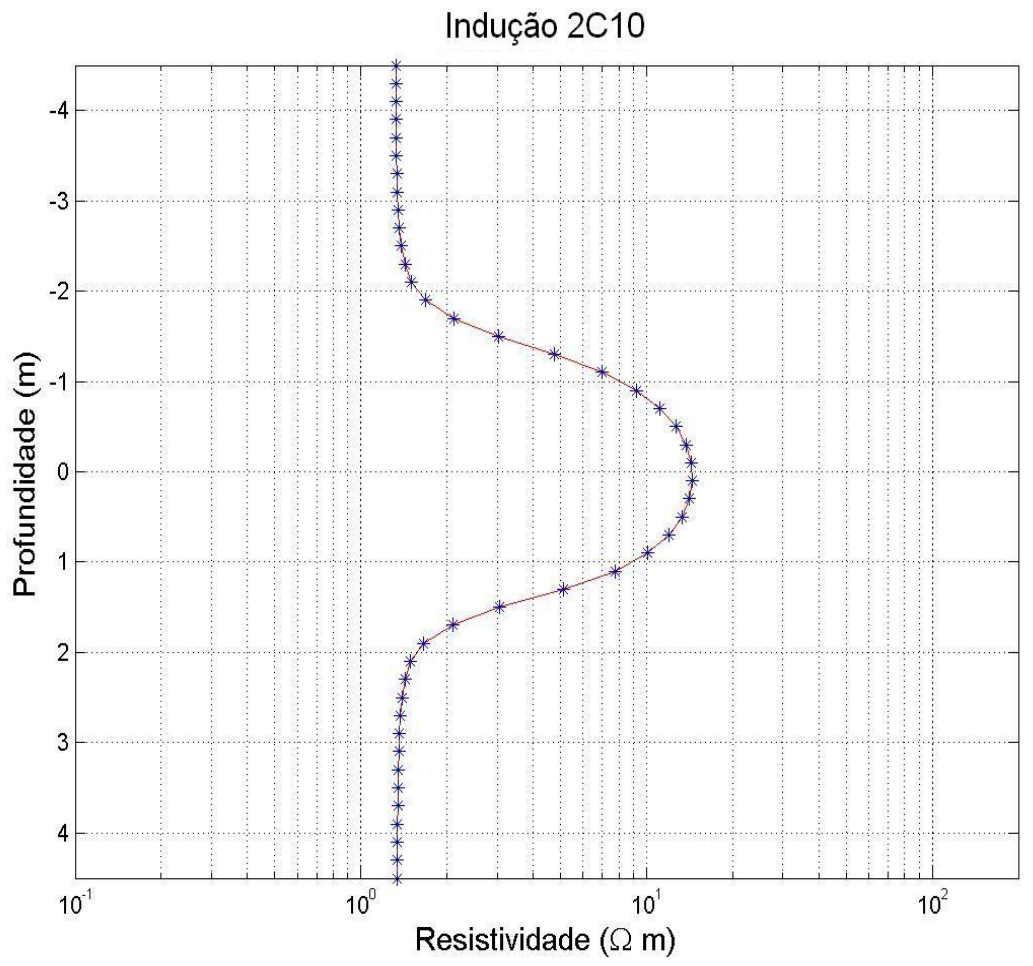

Figura 2. Efeito do microanular.

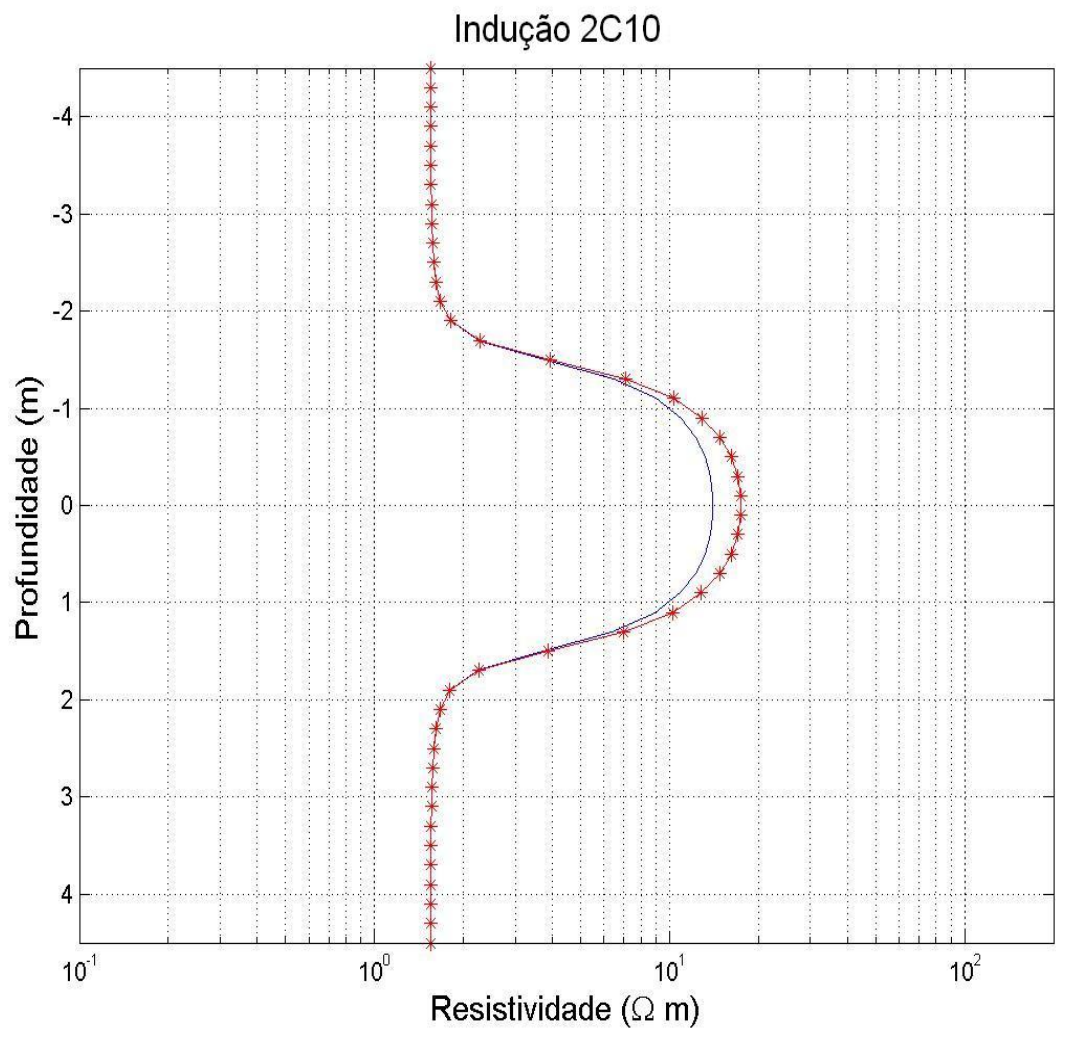

Figura 3. Efeito da presença do reboco. 


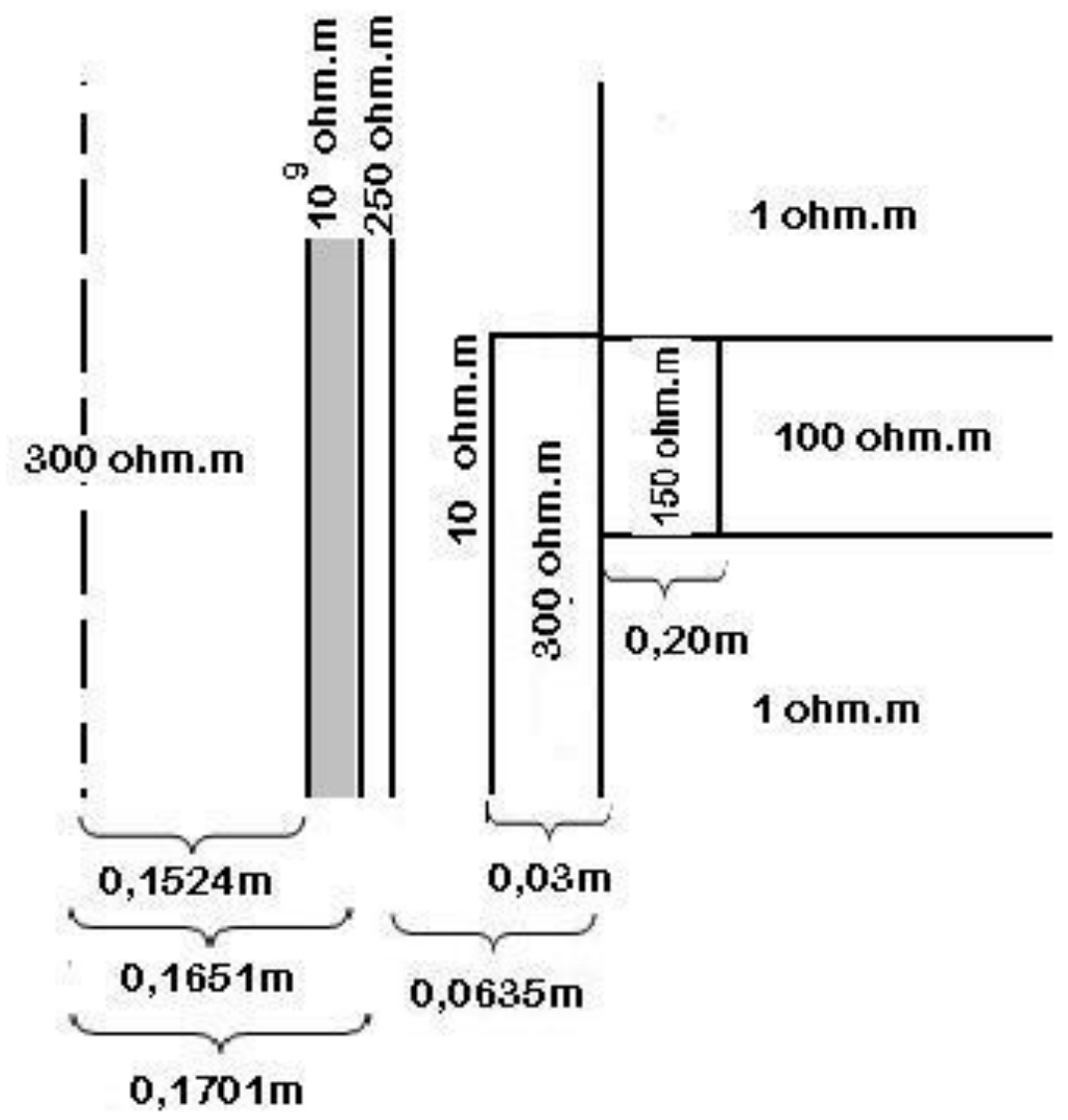

Figura 4. Canalização circular.

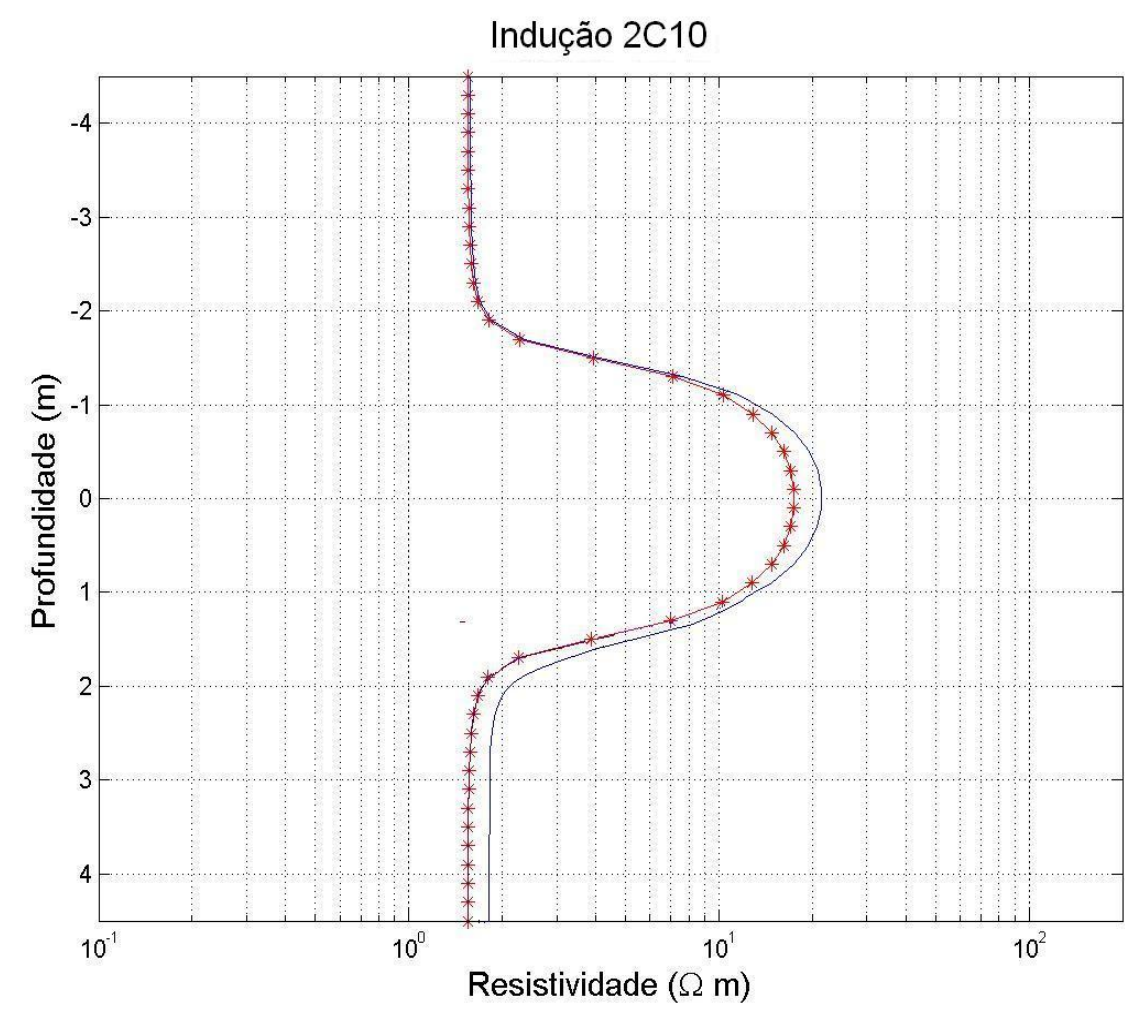

Figura 5. Efeito da canalização circular.

V Simpósio Brasileiro de Geofísica 